\title{
Protocol: An updated integrated methodology for analysis of metabolites and enzyme activities of ethylene biosynthesis
}

\author{
Inge Bulens ${ }^{*}$, Bram Van de Poel ${ }^{1}$, Maarten LATM Hertog ${ }^{1}$, Maurice P De Proft ${ }^{2}$, Annemie H Geeraerd ${ }^{1}$ and
} Bart M Nicolaï ${ }^{1}$

\begin{abstract}
Background: The foundations for ethylene research were laid many years ago by researchers such as Lizada, Yang and Hoffman. Nowadays, most of the methods developed by them are still being used. Technological developments since then have led to small but significant improvements, contributing to a more efficient workflow. Despite this, many of these improvements have never been properly documented.

Results: This article provides an updated, integrated set of protocols suitable for the assembly of a complete picture of ethylene biosynthesis, including the measurement of ethylene itself. The original protocols for the metabolites 1-aminocyclopropane-1-carboxylic acid and 1-(malonylamino)cyclopropane-1-carboxylic acid have been updated and downscaled, while protocols to determine in vitro activities of the key enzymes 1-aminocyclopropane1-carboxylate synthase and 1-aminocyclopropane-1-carboxylate oxidase have been optimised for efficiency, repeatability and accuracy. All the protocols described were optimised for apple fruit, but have been proven to be suitable for the analysis of tomato fruit as well.
\end{abstract}

Conclusions: This work collates an integrated set of detailed protocols for the measurement of components of the ethylene biosynthetic pathway, starting from well-established methods. These protocols have been optimised for smaller sample volumes, increased efficiency, repeatability and accuracy. The detailed protocol allows other scientists to rapidly implement these methods in their own laboratories in a consistent and efficient way.

Keywords: Ethylene, ACC, ACS, ACO, MACC

\section{Background}

Ethylene biosynthesis starts from the conversion of Sadenosyl-L-methione (SAM) into 1-aminocyclopropane1-carboxylic acid (ACC) by the enzyme 1-aminocyclopropane-1-carboxylate synthase (ACS). ACC can then be converted to either 1-(malonylamino)cyclopropane-1carboxylic acid (MACC) by ACC N-Malonyl transferase, or to the end product, ethylene, by 1-aminocyclopropane-1-carboxylate oxidase (ACO) [1] (Figure 1).

Analytical protocols for each of these metabolites and enzymes have been developed and are available. The easiest component to measure is the gaseous hormone

\footnotetext{
* Correspondence: inge.bulens@biw.kuleuven.be

'Division of Mechatronics, Biostatistics and Sensors (MeBioS), Department of Biosystems (BIOSYST), Katholieke Universiteit Leuven, Willem de Croylaan 42, bus 2428, B-3001 Leuven, Belgium

Full list of author information is available at the end of the article
}

ethylene. It is formed inside cells, diffuses through the tissue and eventually out of the fruit into the surrounding atmosphere. Therefore multiple readings can be made without destructive sampling of the tissue. Typically, measurements are performed by gas chromatography $(\mathrm{GC})[2,3]$ or more recently by techniques such as photo acoustic laser spectrophotometry (PALS) [4]. Both techniques are easy to use. PALS generally offers a higher detection sensitivity (ppt level; $1: 10^{12}$ ) compared to GC (ppb level; $1: 10^{9}$ ). However, GC equipment can be used for a broader range of applications while laser based sensors are highly selective for a specific compound.

In 1979, Lizada and Yang published a method to quantify ACC indirectly by liberating ethylene from ACC with $\mathrm{NaOCl}$ in the presence of $\mathrm{Hg}^{2+}[5]$. Since

\section{Ciomed Central}




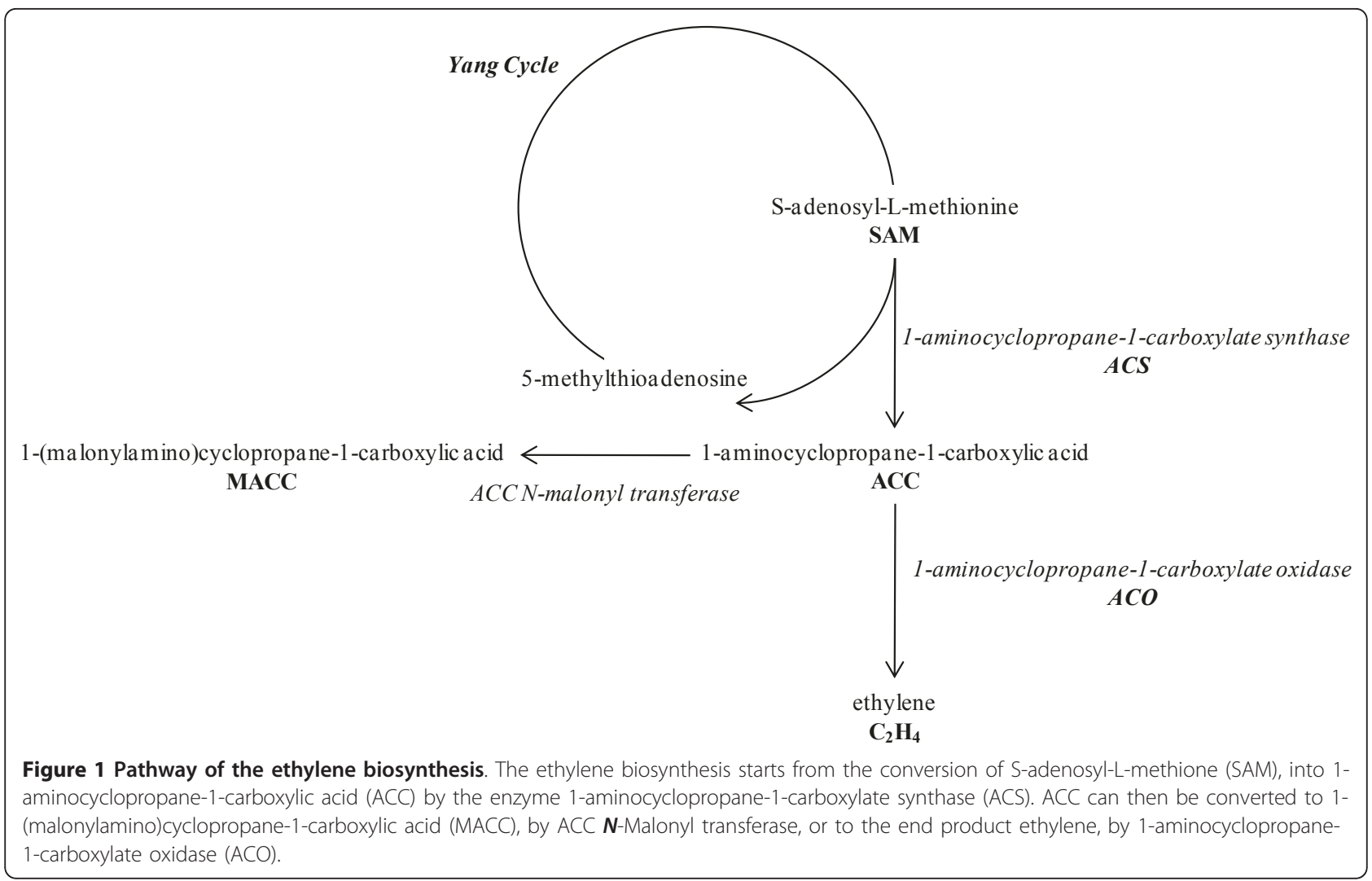

then, several methods have been published that allow the direct quantification of ACC by gas chromatography-mass spectrometry (GC-MS) [6], liquid chromatography-mass spectrometry (LC-MS) [7] or capillary electrophoresis with laser-induced fluorescence detection (CE-LIF) [8]. Each technique has its own advantages and disadvantages. For GC-MS and CE-LIF analysis samples need to be derivatised before measurement, which makes the procedure quite complex and time-consuming. The main disadvantage however is the poor reproducibility of the derivatisation procedure when dealing with low ACC concentrations. ACC contents can be directly measured using LC-MS, but the technique is very expensive, both in terms of the equipment required as well as the consumables. This makes LC-MS unfavourable when large amounts of samples are involved. Even though the procedure of Lizada and Yang measures ACC indirectly, it allows for relatively fast measurements with little sample preparation and using low cost equipment. If the fluctuating efficiency of the turnover reaction is taken into account in a proper way, following the protocol outlined in the present manuscript, the technique provides a convenient and accurate way to quantify ACC in, for example, fruit samples.
Hoffman and Yang discovered in 1982 that ACC is not only converted into ethylene but that a large amount of the formed ACC is converted into MACC [9]. They quantified MACC by subtracting the amount of ACC present, prior to and following acidic hydrolysis of the extract, according to the method of Lizada and Yang. The protocol outlined here is based on this original method and provides a rapid procedure to quantify MACC starting from small amounts of ACC extract.

For the quantification of in vitro ACS and ACO activity, the protocols presented here are based on more recent work of Vilaplana [10] and Dandekar [11]. The optimisation of these protocols has focussed on volume reductions, the elimination of superfluous handlings and an increased efficiency. Changes have been also made to improve the reproducibility and accuracy of these measurements.

SAM is a less well-studied ethylene precursor, mainly because it is more difficult to quantify [12]. The influence of SAM on ethylene biosynthesis is therefore not known and very often neglected. Recently a paper was published that describes a rapid procedure to quantify SAM by CE-UV [13]. This protocol is compatible with the other protocols described below. 


\section{Results}

\section{Protocol 1 - Ethylene measurement}

The measurement of ethylene in the headspace surrounding a sample is quite straightforward, nevertheless it is difficult to directly compare results obtained from different laboratories. For example, when ethylene production is expressed in terms of volume of gas produced, without additional information on the temperature and pressure present during the experimental setup, it cannot be unambiguously related to results expressed in molar units. Ethylene concentrations are quantified by GC. Calibration is done by defining the linear relation between peak area and the known ethylene concentration (ppm) of at least three different calibration concentrations covering the entire detector response range. Before each set of measurements the calibration curve needs to be validated again.

\section{Ethylene production rate of intact fruits}

1. Fruits are individually enclosed in air tight jars of 1.7 $\mathrm{L}$ and flushed for a defined number of hours with humidified air of the desired gas composition until steady state conditions are reached between the headspace and the fruit's internal atmosphere.

2. After flushing, the inlet and outlet of the jar are closed. Before sampling, the pressure inside the jar is measured and subsequently an initial sample of the headspace is taken for GC analysis, using the sampling port of the jar. Here, a total sample volume of $10 \mathrm{~mL}$ is extracted to allow proper flushing of the equipment tubing between subsequent samples. After sampling, the pressure inside the jar is again measured. The pressure readings are used to check whether a correct sample is taken, whether the jar is airtight, and to be able to express the amount of ethylene present in molar units using the ideal gas law $(p . V=n \cdot R \cdot T)$.

3. After an experimentally determined period of time, a second measurement of the headspace is performed, as described in step 2. The length of the period between the two measurements depends on the rate of ethylene production by the sample as the accumulation of ethylene concentrations in the jar has to be sufficiently high to be detectable, but not too high to influence behaviour of the samples. In the case of apples, this was determined to be between 4 and $14 \mathrm{~h}$ depending on the ripening stage and the type of experiment. NOTE: Shorter accumulation periods can also be reached by decreasing the ratio free headspace to total volume of the jar used.

4. Based on the difference between the final ethylene reading $E t h_{\mathrm{c}, \mathrm{f}}(\mathrm{ppm})$ and the initial reading $E t h_{\mathrm{c}, \mathrm{i}}(\mathrm{ppm})$, and taking into account the weight of the apple $w(\mathrm{~kg})$, the free volume of the jar $V_{\text {free }}\left(\mathrm{m}^{3}\right)$, the temperature $T$ $(\mathrm{K})$ and the pressure after the first measurement $p_{\mathrm{i}}(\mathrm{Pa})$ and before the second measurement $p_{\mathrm{f}}(\mathrm{Pa})$, the ethylene production rate $E t h_{\mathrm{pr}}\left(\mathrm{mol} . \mathrm{kg}^{-1} \cdot \mathrm{h}^{-1}\right)$ is calculated as follows:

$$
\begin{aligned}
& E t h_{\mathrm{pr}}=\frac{n_{\mathrm{eth}, \mathrm{f}}-n_{\mathrm{eth}, \mathrm{i}}}{w \cdot t} \\
& n_{\mathrm{eth}, \mathrm{f}}=E t h_{\mathrm{c}, \mathrm{f}} \cdot 10^{-6} \cdot n_{\mathrm{t}}=E t h_{\mathrm{c}, \mathrm{f}} \cdot 10^{-6} \cdot \frac{p_{\mathrm{f}} \cdot V_{\text {free }}}{R \cdot T} \\
& n_{\mathrm{eth}, \mathrm{i}}=E t h_{\mathrm{c}, \mathrm{i}} \cdot 10^{-6} \cdot n_{\mathrm{t}}=E t h_{\mathrm{c}, \mathrm{i}} \cdot 10^{-6} \cdot \frac{p_{\mathrm{i}} \cdot V_{\text {free }}}{R \cdot T}
\end{aligned}
$$

With $n_{\text {eth, }}$ and $n_{\text {eth, i }}$ being the ethylene concentration $(\mathrm{mol}), n_{\mathrm{t}}$ being the total amount of gas in the recipient (mol), $t$ being the time between the two readings (h) and $R$ the universal gas constant $\left(8.314 \mathrm{~J} \cdot \mathrm{mol}^{-1} \cdot \mathrm{K}^{-1}\right)$.

\section{Ethylene production for ACC and ACO assays}

As will be described in the protocols for the quantification of ACC and the in vitro activity of ACO, ethylene production in these assays is measured in a $20 \mathrm{~mL}$ glass GC-vial. Due to the small headspace volume an adapted GC method is used where only a small volume of headspace is extracted $(3 \mathrm{~mL})$. For the same reason no initial reading is taken and the initial concentration of ethylene in the vial is assumed to be zero.

Again, pressure is measured before and after sampling to control air tightness and ensure correct sampling. Ethylene production is then expressed in moles taking into account temperature, pressure and headspace volume as described in equations 1 and 2 with $n_{\text {eth, i }}$ being zero.

\section{Protocol 2 - Quantification of ACC and MACC}

The two extraction solutions generally used for ACC (and MACC) are sulfosalicylic acid (SSA) and ethanol. In terms of yield, both extraction solutions give similar results, but the repeatability for the SSA extraction is much higher than for the ethanol extraction (data not shown). Another advantage of the SSA extraction is that it is a cold extraction not requiring an evaporation step. This makes the extraction procedure much faster and less laborious. Tests showed that longer extraction times, multiple extraction steps and filtration of the extracts are redundant.

The conversion efficiency of ACC to ethylene in the ACC extracts is matrix, and thereby sample, dependent. For this reason it is essential to measure for each extract an additional spiked sample (with a known amount of ACC added) to determine the reaction efficiency.

\section{Preparation of the solutions}

1. SSA $(5 \% \mathrm{~m} / \mathrm{v})$ : Dissolve $5 \mathrm{~g}$ of sulfosalicylic acid in a total volume of $100 \mathrm{~mL}$ distilled water. 
2. $\mathrm{HgCl}_{2}(10 \mathrm{mM})$ : Dissolve $0.271 \mathrm{~g}$ of mercury chloride in a total volume of $100 \mathrm{~mL}$ distilled water. NOTE: This compound is toxic, be sure to read and follow the safety and disposal guidelines provided by the manufacturer with care.

3. $\mathrm{NaOCl}(5 \% \mathrm{v} / \mathrm{v})$ : Add $5 \mathrm{~mL}$ of sodium hypochlorite to $95 \mathrm{~mL}$ distilled water.

4. $\mathrm{NaOH}(6 \mathrm{M})$ : Dissolve $24 \mathrm{~g}$ of sodium hydroxide in a total volume of $100 \mathrm{~mL}$ distilled water.

5. $\mathrm{HCl}(6 \mathrm{M})$ : Dilute a $37 \%$ solution of hydrogen chloride to $22 \%$ by slowly adding $60 \mathrm{~mL}$ of the solution to $40 \mathrm{~mL}$ of distilled water.

6. $\mathrm{NaOCl}-\mathrm{NaOH}$ mixture $(2: 1, \mathrm{v} / \mathrm{v})$ : Add two units of $\mathrm{NaOCl}$ to one unit of $\mathrm{NaOH}$ and keep on ice. NOTE: Prepare a fresh $\mathrm{NaOCl}-\mathrm{NaOH}$ mixture every day.

7. ACC $(50 \mu \mathrm{M})$ : Make a stock solution of $10 \mathrm{mM}$ by dissolving $2 \mathrm{mg}$ of ACC in $2 \mathrm{~mL}$ distilled water. Dillute the stock solution to $50 \mu \mathrm{M}$. NOTE: Store the ACC solution at $-20^{\circ} \mathrm{C}$.

\section{Extraction}

See Figure 2

1. Weigh $2 \mathrm{~g}$ of crushed, frozen tissue in a $15 \mathrm{~mL}$ falcon tube cooled in liquid nitrogen. Store in liquid nitrogen or at $-80^{\circ} \mathrm{C}$ until extraction.

2. Add $4 \mathrm{~mL}$ of $5 \%$ SSA solution to the frozen sample. Vortex until a homogeneous mixture is obtained.

3. Allow $30 \mathrm{~min}$ for the extraction to take place while gently shaking the sample at $4^{\circ} \mathrm{C}$.
4. Centrifuge the sample for $10 \mathrm{~min}$ at $3,090 \times \mathrm{g}$ in a precooled centrifuge at $4^{\circ} \mathrm{C}$. Collect the supernatant (around 4.5 to $5 \mathrm{~mL}$ ) in a clean $15 \mathrm{~mL}$ falcon.

5. Separate $0.5 \mathrm{~mL}$ of the collected supernatant in a $1.5 \mathrm{~mL}$ microcentrifuge tube for acidic hydrolysis to liberate MACC.

6. Store both the falcon and the microcentrifuge tube in liquid nitrogen or at $-80^{\circ} \mathrm{C}$ until performing the next steps of the protocol.

\section{Acidic hydrolysis}

1. Heat the water bath to $99^{\circ} \mathrm{C}$.

2. Thaw the microcentrifuge tube containing $0.5 \mathrm{~mL}$ of ACC extract and add $0.2 \mathrm{~mL}$ of $6 \mathrm{M} \mathrm{HCl}$. Vortex the sample to homogenise the solution.

3. Put the microcentrifuge tube in the water bath (using floating holders) and allow $3 \mathrm{~h}$ for the reaction. NOTE: Shortly after placing the microcentrifuge tube in the water bath it might pop open due to the sudden change in temperature. It is recommended to use safe lock microcentrifuge tubes to avoid popping of the tubes.

4. After $3 \mathrm{~h}$, remove the microcentrifuge tubes from the water bath and allow them to cool down for $15 \mathrm{~min}$ at room temperature. Add $0.2 \mathrm{~mL}$ of $6 \mathrm{M} \mathrm{NaOH}$ and vortex briefly. NOTE: This step is performed to neutralize the sample and results in a dark brown solution.

5. Centrifuge the microcentrifuge tube for $5 \mathrm{~min}$ at $22,000 \times$ g. Discard the brown pellet and collect the yellow supernatant.

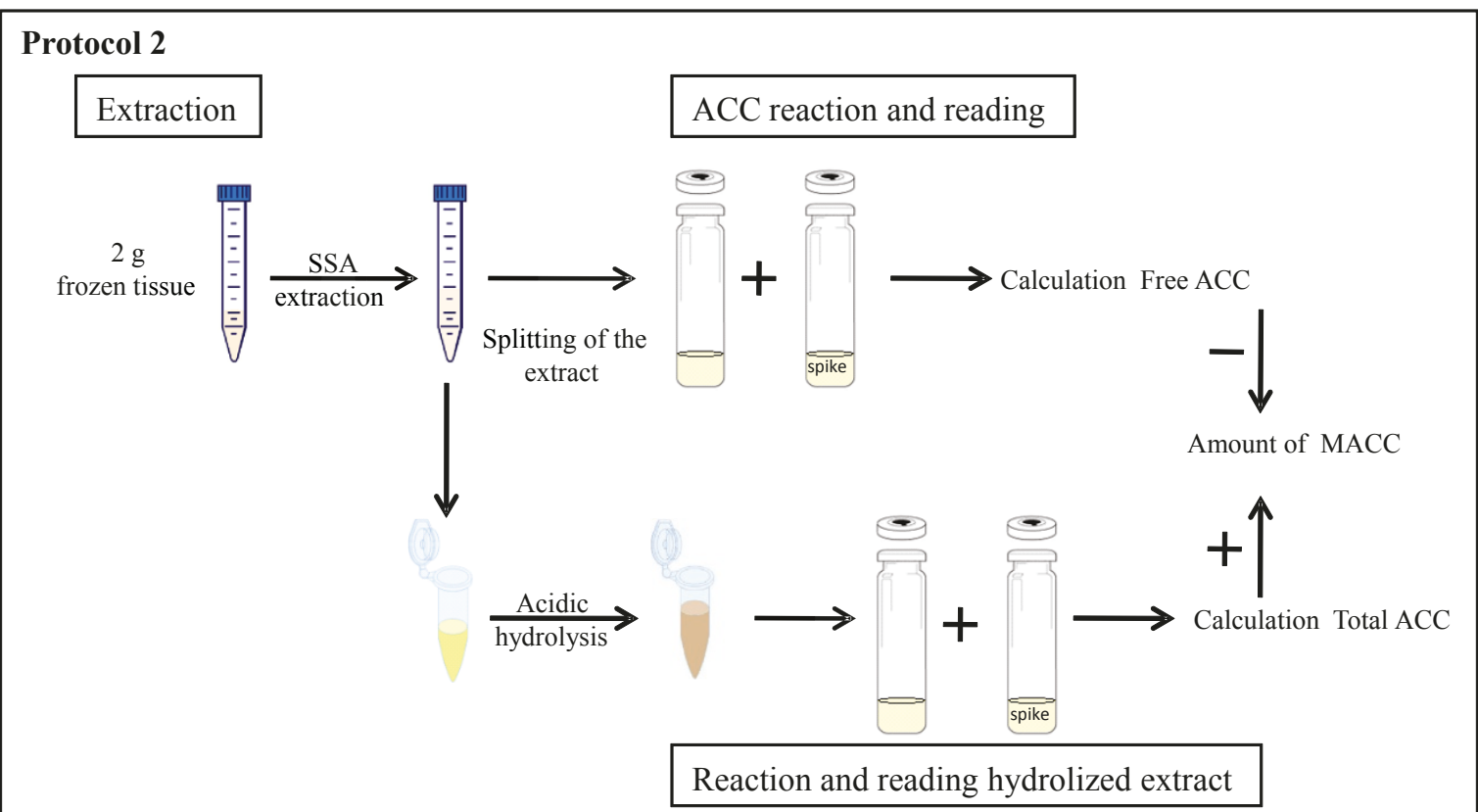

Figure 2 Schematic overview of the ACC and MACC protocol (protocol 2). Following extraction of tissue with SSA, the extract is divided into two aliquots. The first aliquot is used for the determination of the free ACC content of the sample, while the second is first hydrolysed, before the total ACC content of the sample is measured. The MACC concentration of the sample is calculated by subtracting the free ACC concentration from the total ACC concentration. 
6. Store the supernatant at $-20^{\circ} \mathrm{C}$ until performing the reaction step.

\section{Reaction and reading of the ACC extract}

Because the efficiency of the reaction to turn ACC into ethylene is sample dependent, each sample should be analysed twice. In the second measurement, a known amount of ACC is added to the extract (step 3 in de reaction protocol described below). Based on the results of both reactions, the efficiency which is used to correct the final outcome is then determined for each individual sample.

1. Thaw the sample on ice.

2. Bring $1.4 \mathrm{~mL}$ of the ACC extract in a glass vial (e.g. $20 \mathrm{~mL}$ )

3. If necessary spike the sample by adding $20 \mu \mathrm{L}$ of a $50 \mu \mathrm{M}$ ACC solution. NOTE: The amount of ACC added by spiking should be in the similar concentration range as the natural occurring ACC content of the sample itself.

4. Add $0.4 \mathrm{~mL}$ of $10 \mathrm{mM} \mathrm{HgCl}_{2}$ and immediately seal the vial airtight with a septum containing cap.

5. Inject $0.2 \mathrm{~mL}$ of the $\mathrm{NaOH}-\mathrm{NaOCl}$ mixture through the septum of the cap using a needle and syringe. NOTE: The turnover of the reaction is highly dependent on the amount of $\mathrm{NaOH}-\mathrm{NaOCl}$ mixture added. So it is very important to add the required amount as accurately as possible.

6. Vortex the sample for 5 seconds and allow it to react for $4 \mathrm{~min}$ on melting ice.

7. Vortex the sample again for 5 seconds to release all ethylene into the vial headspace. NOTE: The reaction time and the time taken to vortex must be controlled with great care to minimise errors.

8. Immediately take a sample of the headspace for GC analysis of the content. NOTE: During the 4 min reaction time another sample can be prepared. Ensure that the time between sample processing is sufficient to perform the GC analysis. NOTE: Each time a new ACC solution to spike is prepared, three blank spiked samples should be tested (by replacing extract with water) to calibrate the concentration of the spike. We assume 100\% reaction efficiency in water.

\section{Reaction and reading of the hydrolysed ACC extract}

Except for the volumes added, this reaction is identical to the one for the ACC extract, with again every sample being analysed twice (either spiked or not with a known amount of ACC). Instead of the $1.4 \mathrm{~mL}$ of extract (step 2) use $0.6 \mathrm{~mL}$ distilled water, with $0.1 \mathrm{~mL}$ hydrolysed extract. Instead of the $0.4 \mathrm{~mL} \mathrm{HgCl}_{2}$ (step 4) add 0.2 $\mathrm{mL} \mathrm{HgCl}_{2}$. During step 5, after sealing the vial, $0.1 \mathrm{~mL}$ of the $\mathrm{NaOH}-\mathrm{NaOCl}$ mixture is injected through the septum of the cap.

NOTE: The reduction in the amount of extract and the addition of water, compared to the reaction of the
ACC extract, is done to increase the reaction efficiency to about $70 \%$. Adding more extract (containing more ACC) will only lead to a higher ethylene production if the efficiency of the reaction is kept high enough. This is done by diluting the extract with water, and by proportionally increasing the amount of $\mathrm{HgCl}_{2}$ and $\mathrm{NaOH}-\mathrm{NaOCl}$ mixture.

NOTE: The blank spike value has to be determined separately for the hydrolysed samples because it will differ slightly with the one for the non hydrolysed extracts due to small changes in the amount of added products.

\section{Calculation of ACC and MACC concentration}

Based on the GC readings of the sample $E t h_{\text {sample }}$ and the spiked sample $E t h_{\text {spike }}(\mathrm{ppm})$, the number of moles ethylene formed, $n_{\text {sample }}$ and $n_{\text {spike }}$ can be calculated as follows:

$$
\begin{aligned}
& n_{\text {sample }}=E t h_{\text {sample }} \cdot 10^{-6} \cdot \frac{p_{\mathrm{i}} \cdot V_{\text {free }}}{R \cdot T} \\
& n_{\text {spike }}=E t h_{\text {spike }} \cdot 10^{-6} \cdot \frac{p_{\mathrm{i}} \cdot V_{\text {free }}}{R \cdot T}
\end{aligned}
$$

with $V_{\text {free }}$ being the volume of the GC vial minus the total amount of liquids added $\left(\mathrm{m}^{3}\right), p_{\mathrm{i}}$ the pressure before sample taking, $T$ the temperature $(273 \mathrm{~K})$ and $R$ the universal gas constant $\left(8.314 \mathrm{~J} \cdot \mathrm{mol}^{-1} \cdot \mathrm{K}^{-1}\right)$.

For each sample the reaction efficiency (Eff) of the ACC turnover can be calculated as:

$$
E f f=\frac{n_{\text {spike }}-n_{\text {sample }}}{n_{\text {blank }}}
$$

with $\mathrm{n}_{\text {blank }}$ being the average of the amount of moles ethylene formed in the three blank samples containing only spiking solution.

Taking into account the amount of extract used for the reading $V_{\text {reading, }}$, the total volume of liquid in the sample after extraction (considering the water content of the tissue) $V_{\text {extract }}$ and the weight of the used sample $w$, the amount of $A C C$ in the sample (mol.g $\mathrm{FW}^{-1}$ ) equals:

$$
A C C=\frac{n_{\text {sample }} \cdot V_{\text {extract }}}{V_{\text {reading }} \cdot E f f \cdot w}
$$

The amount of MACC in the sample is calculated by subtracting the free ACC concentration $\left(A C C_{\text {free }}\right)$ from the hydrolysed ACC concentration $\left(A C C_{\text {tot }}\right)$ :

$$
M A C C=A C C_{\text {tot }}-A C C_{\text {free }}
$$

\section{Protocol 3 - In vitro activity of ACS}

The quantification of in vitro ACC synthase activity is the most time consuming and extensive protocol since 
it requires enzyme extraction, cleaning up of the extract (to discard endogenous ACC and other interfering compounds), and a two step reaction to convert SAM via ACC into ethylene.

Compared to the original protocol, less starting material is needed and time consuming steps, such as filtering through cheesecloth, were shown to be redundant. Tests indicated that it is possible to store extracts and reacted samples at $-80^{\circ} \mathrm{C}$ without affecting the measured activity or influencing any further steps. This allows for a more time efficient approach since different parts of the protocol can now be performed over different days with an optimised number of samples.

A schematic overview of the protocol is given in Figure 3.

\section{Preparation of the solutions}

1. Tricine extraction buffer (200 mM, pH 8.5): Dissolve $8.96 \mathrm{~g}$ of Tricine in distilled water, adjust to $\mathrm{pH} 8.5$, add distilled water up to a total volume of $250 \mathrm{~mL}$.

2. Tricine reaction buffer (200 mM, pH 8.0): Dissolve $8.96 \mathrm{~g}$ of Tricine in distilled water, adjust to $\mathrm{pH} 8.0$, add distilled water up to a total volume of $250 \mathrm{~mL}$.

3. Tricine column buffer ( $5 \mathrm{mM}, \mathrm{pH} 8.0$ ): Dissolve $0.224 \mathrm{~g}$ of Tricine in distilled water, adjust to $\mathrm{pH} 8.0$, and add distilled water up to a total volume of $250 \mathrm{~mL}$.
4. PLP (2 mM): Dissolve $2.47 \mathrm{mg}$ of pyrodoxal-Lphosphate (PLP) in a total volume of $5 \mathrm{~mL}$ distilled water.

5. Extraction solution: Add $150 \mu \mathrm{l}$ PLP ( $2 \mathrm{mM})$ and $115.5 \mathrm{mg}$ of DTT $(10 \mathrm{mM})$ to $75 \mathrm{~mL}$ of Tricine extraction buffer (200 mM, pH 8.5)

6. Column solution: Add $405 \mu \mathrm{l}$ PLP $(2 \mathrm{mM})$ and 62.6 mg of DTT (1 mM) to $405 \mathrm{~mL}$ of Tricine column buffer (5 mM, pH 8).

NOTE: Prepare PLP and consequently all extraction and column solutions fresh daily.

7. $\mathrm{HgCl}_{2}(100 \mathrm{mM})$ : Dissolve $2.71 \mathrm{~g}$ of mercury chloride in a total volume of $100 \mathrm{~mL}$ of distilled water.

8. $\mathrm{NaOCl}-\mathrm{NaOH}$ mixture $(2: 1, \mathrm{v} / \mathrm{v})$ : prepare as described for the ACC protocol.

9. SAM chloride (1.2 mM): Dissolve $13 \mathrm{mg}$ of SAM chloride in a total volume of $25 \mathrm{~mL}$ distilled water. Vortex until all powder is dissolved, then divide into 20 aliquots of $1.25 \mathrm{~mL}$ using microcentrifuge tubes and store at $-80^{\circ} \mathrm{C}$.

NOTE: Be sure to use SAM chloride and not SAM iodide; with SAM iodide ACC synthase does not seem to react.

\section{Extraction and purification}

1. Weigh $15 \mathrm{mg}$ of polyvinylpyrrolidone (PVP) in a 15 $\mathrm{mL}$ falcon.

\section{Protocol 3}

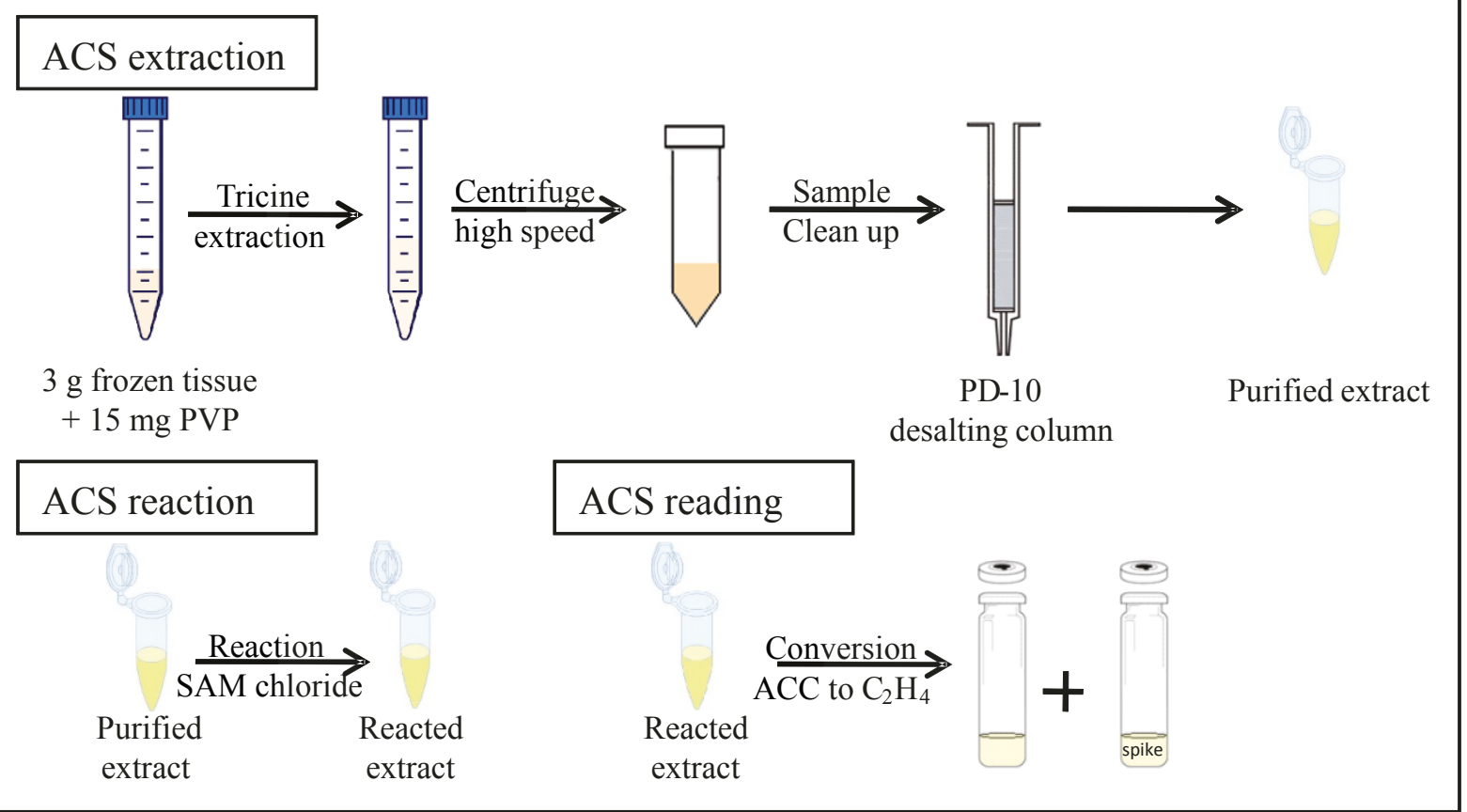

Figure 3 Schematic overview of the ACS protocol (protocol 3). Following tricine extraction of the tissue, a sample clean up on a PD-10 desalting column is performed to remove salts and ACC from the extract. After reaction of the purified extract with SAM chloride, the amount of ACC formed is quantified by chemically converting it into ethylene. 
2. Add $3 \mathrm{~g}$ of frozen crushed sample to the tube containing PVP after cooling the falcon in liquid nitrogen.

3. Add $3 \mathrm{~mL}$ of extraction solution and vortex until a homogeneous mixture is obtained.

NOTE: It is important the keep the sample on ice to avoid loss of activity.

4. Centrifuge the sample for $20 \mathrm{~min}$ at $24,414 \times \mathrm{g}$ at 4 ${ }^{\circ} \mathrm{C}$ (cool rotor in advance). Collect $3 \mathrm{~mL}$ of the supernatant in a cooled $15 \mathrm{~mL}$ falcon.

5. Load $2.5 \mathrm{~mL}$ of the supernatant on a Sephadex G25 desalting column for sample clean up. Elute the sample from the column with $3.5 \mathrm{~mL}$ of the same column solution and collect this fraction in a cooled falcon (keep on ice). NOTE: The columns are disposable but can be reused about four times. They should be discarded when flow through becomes very slow. The columns can be stored at $4^{\circ} \mathrm{C}$ after adding $2 \mathrm{~mL}$ of column solution to prevent drying out. Equilibrate the columns before every use with $10 \mathrm{~mL}$ of column solution.

6. Transfer $1.5 \mathrm{~mL}$ of the eluate in two separate $2 \mathrm{~mL}$ microcentrifuge tubes (one of them to be used for the reaction, the other as a spare). Immediately snap freeze in liquid nitrogen to avoid loss of activity. The purified extract can be stored at $-80^{\circ} \mathrm{C}$ until reaction is performed.

\section{Reaction}

1. Thaw the purified extract on ice.

2. Add $150 \mu \mathrm{L}$ of Tricine reaction buffer and $150 \mu \mathrm{L}$ of SAM chloride to the $1.5 \mathrm{~mL}$ extract, vortex briefly.

3. Allow the sample to incubate in a thermo mixer for $2 \mathrm{~h}$ at $25^{\circ} \mathrm{C}$ while gently shaking. The ACC synthase will now convert part of the excess SAM substrate into ACC.

4. After $2 \mathrm{~h}$, remove samples and stop the reaction by adding $200 \mu \mathrm{L}$ of the $100 \mathrm{mM} \mathrm{HgCl}_{2}$ solution. NOTE: The high concentration of $\mathrm{HgCl}_{2}$ stops any enzyme activity.

5. Keep samples on ice if the readings steps take place straight away, otherwise snap freeze in liquid nitrogen and store at $-80^{\circ} \mathrm{C}$.

\section{Reading}

Except for the fact that $\mathrm{HgCl}_{2}$ has already been added to the sample and for the slightly different volumes of reactants added, this reaction is identical to the ones for ACC and the hydrolysed ACC extract. Again every sample is analysed twice (either spiked or not spiked with a known amount of ACC).

Put $850 \mu \mathrm{L}$ distilled water in a $20 \mathrm{~mL}$ glass vial and add $950 \mu \mathrm{L}$ of the reacted extract (in case of the spiked sample add $20 \mu \mathrm{L}$ of a $50 \mu \mathrm{M}$ ACC solution). Seal the vial with a cap and inject $0.2 \mathrm{~mL}$ of the $\mathrm{NaOH}-\mathrm{NaOCl}$ mixture through the septum of the cap. Follow steps 6-8 in "Reaction and reading of the ACC extract" protocol 2 .

\section{Calculation of the in vitro activity of ACS}

The calculation of the amount of moles ethylene formed in the sample $n_{\text {sample }}$ and of the efficiency Eff is described in protocol 2 by equations 4, 5 and 6. Taking into account the amount of extract used in the reading $V_{\text {reading, }}$ the volume of the liquid in the sample after extraction (considering the water content of the tissue) $V_{\text {extract }}$, the dilution factor due to sample clean up on

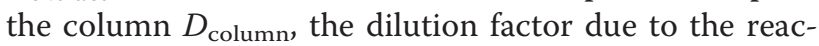

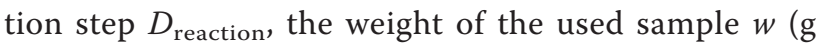
FW) and the incubation time $t(\mathrm{~h})$, ACS activity in the sample (mol.g FW ${ }^{-1} \cdot \mathrm{h}^{-1}$ ) equals:

$$
A C S_{\text {activity }}=\frac{n_{\text {sample }} \cdot V_{\text {extract }} \cdot D_{\text {column }} \cdot D_{\text {reaction }}}{E f f \cdot V_{\text {reading }} \cdot w \cdot t}
$$

with $D_{\text {column }}=1.4$ and $D_{\text {reaction }}=1.33$.

\section{Protocol 4 - In vitro activity of ACO}

In order to quantify the in vitro activity of $\mathrm{ACO}$, the extracted enzyme is incubated with an excess of ACC and the ethylene formed is measured (Figure 4).

Again, the emphasis during protocol optimisation was on scale reduction and an increased efficiency. Tests showed that it is possible to perform the extraction and the reaction on different days, as long as the extracts are immediately frozen in liquid nitrogen. When stored on ice there is a slow but consistent loss of activity. Another aspect that was added to the protocol is the importance of a blank reading. The measurement of blank samples is necessary to incorporate the amount of non-enzymatic ethylene production from the reaction buffer.

\section{Preparation of the solutions}

1. MOPS extraction buffer (400 mM, pH 7.2): Dissolve $8.370 \mathrm{~g}$ of MOPS in $50 \mathrm{~mL}$ of distilled water. Add 10 $\mathrm{mL}$ of glycerol $(10 \% \mathrm{v} / \mathrm{v})$ and $0.594 \mathrm{~g}$ of ascorbic acid sodium salt $(30 \mathrm{mM})$. Homogenise the solution, adjust to $\mathrm{pH} 7.2$, and add distilled water to a total volume of $100 \mathrm{~mL}$.

2. MOPS reaction buffer (50 mM, pH 7.2): Dissolve $1.046 \mathrm{~g}$ of MOPS in $50 \mathrm{~mL}$ of distilled water. Add 10 $\mathrm{mL}$ of glycerol $(10 \% \mathrm{v} / \mathrm{v}), 0.099 \mathrm{~g}$ of ascorbic acid sodium salt ( $5 \mathrm{mM}), 0.168 \mathrm{~g}$ of sodium bicarbonate (20 $\mathrm{mM}), 0.3 \mathrm{mg}$ of iron sulphate $(0.02 \mathrm{mM}), 0.010 \mathrm{~g} \mathrm{ACC}$ $(1 \mathrm{mM})$ and $0.015 \mathrm{~g}$ DTT $(1 \mathrm{mM})$. Homogenise the solution, adjust to $\mathrm{pH} 7.2$, and add distilled water to a total volume of $100 \mathrm{~mL}$.

NOTE: Since ascorbic acid and DTT are very unstable they need to be added shortly before the buffers are used. Preferably buffers are prepared fresh daily and kept cold on ice.

NOTE: For tomato samples better results are obtained when a Tris buffer is used (100 mM, pH 8.0) instead of the described MOPS buffer. 


\section{Protocol 4}

ACO extraction
$0.5 \mathrm{~g}$ frozen tissue
$+50 \mathrm{mg}$ PVPP
$\mathbf{4}$ Schematic overview of the ACO protocol (protocol 4). Following extraction of tissues, MOPS reaction buffer and an excessive
extraction

\section{Extraction}

1. Weigh $50 \mathrm{mg}$ of polyvinylpolypyrrolidone (PVPP) in a $2 \mathrm{~mL}$ microcentrifuge tube. NOTE: PVPP will catch interfering polyphenols what will result in an increase in the observed ACO enzyme activity.

2. Add $500 \mathrm{mg}$ of crushed tissue after cooling the microcentrifuge tube in liquid nitrogen.

3. Add $1 \mathrm{~mL}$ of extraction buffer. Vortex until a homogeneous mixture is obtained.

4. Allow the sample to incubate in a thermo mixer for $10 \mathrm{~min}$ at $4^{\circ} \mathrm{C}$ while gently shaking.

5. Centrifuge the sample for $30 \mathrm{~min}$ at $22,000 \times \mathrm{g}$ in a precooled centrifuge at $4^{\circ} \mathrm{C}$, discard the pellet and collect the supernatant (around $800 \mu \mathrm{l}$, depending on the water content of your sample) in a $1.5 \mathrm{~mL}$ microcentrifuge tube.

6. Keep the sample on ice if the reading takes place immediately after. Otherwise snap freeze in liquid nitrogen and store at $-80^{\circ} \mathrm{C}$.

NOTE: Be sure to keep the sample cold or on ice during and in between the extraction steps to avoid loss of activity.

\section{Reaction and Reading}

1. Thaw the frozen extract on ice.

2. Add $3.6 \mathrm{~mL}$ of MOPS reaction buffer together with $400 \mu \mathrm{l}$ of extract in a $20 \mathrm{~mL}$ glass vial, close immediately with a disposable cap.

3. Vortex for 5 seconds to homogenise the mixture.

4. Allow the sample to incubate in a water bath for exactly $1 \mathrm{~h}$ at $30^{\circ} \mathrm{C}$ while gently shaking.

5. Vortex again for 5 seconds, to release all ethylene into the vial headspace. NOTE: It is very important that vortexing is always done in the same way and for the same duration because it can have a significant influence on the reading of the ethylene concentration.
6. Immediately take a sample of the headspace with the $\mathrm{GC}$ to analyse ethylene levels.

NOTE: Before and after a series of measurements (for example 30 readings) it is important to measure a blank sample (3.6 $\mathrm{mL}$ reaction buffer $+0.4 \mathrm{~mL}$ distilled water) since small amounts of ethylene can be formed by the buffer due to non-enzymatic interactions between the reagents. Values obtained for the blank samples typically vary between 15 and 50 ppb ethylene. The amount of ethylene formed by the buffer can change over time. By measuring how the blank value changes over time, a distinction can be made between ethylene production from the buffer itself and ethylene production due to the ACC oxidase activity in the extract.

\section{Calculation of the in vitro activity of ACO}

The amount of ethylene formed $n_{\text {sample }}(\mathrm{mol})$ taking into account the non-enzymatic formation of ethylene can be calculated as follows:

$$
n_{\text {sample }}=\left(E t h_{\text {sample }}-\frac{E t h_{\text {blank }}}{2}\right) \cdot 10^{-6} \cdot \frac{p_{\mathrm{i}} \cdot V_{\text {free }}}{R \cdot T}
$$

Table 1 Overview of the expected range for unripe and ripe apple and tomato fruit

\begin{tabular}{lllll}
\hline & \multicolumn{2}{c}{ Apple } & \multicolumn{2}{c}{ Tomato } \\
\cline { 2 - 5 } & Unripe & Ripe & Unripe & Ripe \\
\hline Ethylene production rate (nmol/kg.s) & 0.0001 & 1.228 & 0.0014 & 0.0361 \\
\hline ACS activity (nmol ACC/kg.s) & $<0.004$ & 1.069 & 0.004 & 0.017 \\
\hline ACC $(\mathrm{nmol} / \mathrm{g})$ & 0.08 & 1.19 & 0.05 & 2.55 \\
\hline MACC $(\mathrm{nmol} / \mathrm{g})$ & 1.32 & 35.77 & 1.00 & 20.00 \\
\hline ACO activity $\left(\mathrm{nmol} \mathrm{C}_{2} \mathrm{H}_{4} / \mathrm{kg} . \mathrm{s}\right)$ & 0.032 & 1.191 & 0.222 & 0.889 \\
\hline
\end{tabular}

All values are an average of 8 repetitions of fruits of the same ripening stage. 
Table 2 List of chemical components used

\begin{tabular}{lcccc}
\hline Name & Abbreviation & CAS number & MW & Company \\
\hline 1-Aminocyclopropane-1-carboxylic acid & ACC & $22059-21-8$ & 101.10 & Acros Organics (Geel, Belgium) \\
\hline 3-Morpholinopropane-1-sulfonic acid & MOPS & $1132-61-2$ & 209.27 & Applichem (MWR, Leuven, Belgium) \\
\hline Ascorbic acid sodium salt & & $134-03-2$ & 198.11 & Fluka (Sigma-Aldrich, St Louis, MO, USA) \\
\hline Dithiothreitol & DTT & $3483-12-3$ & 154.26 & Sigma-Aldrich (St Louis, MO, USA) \\
\hline Glycerol & & $56-81-5$ & 92.09 & Acros Organics (Geel, Belgium) \\
\hline Hydrogen chloride (37\%) & $\mathrm{HCl}$ & $7647-01-0$ & 36.46 & Acros Organics (Geel, Belgium) \\
\hline Iron Sulphate & & $7720-78-7$ & 151.91 & Acros Organics (Geel, Belgium) \\
\hline Mercury chloride & $\mathrm{HgCl} 2$ & $7487-94-7$ & 271.52 & Acros Organics (Geel, Belgium) \\
\hline Polyvinylpyrrolidone & $\mathrm{PVP}$ & $9003-39-8$ & & Applichem (MVR, Leuven, Belgium) \\
\hline Polyvinylpolypyrrolidone & $\mathrm{PVPP}$ & $94800-10-9$ & & Applichem (MWR, Leuven, Belgium) \\
\hline Pyridoxal-L-phosphate & $\mathrm{PLP}$ & $54-47-7$ & 271.14 & Sigma-Aldrich (St Louis, MO, USA) \\
\hline S-(5-Adenosyl)-L-methionine chloride & SAM chloride & $24346-00-7$ & 434.90 & Sigma (Sigma-Aldrich, St Louis, MO, USA) \\
\hline Sodium bicarbonate & & $144-55-8$ & 84.01 & Fluka (Sigma-Aldrich, St Louis, MO, USA) \\
\hline Sodium hydroxide & NaOH & $1310-73-2$ & 40.00 & Thermo Fisher Scientific (Waltham, MA, USA) \\
\hline Sodium hypochlorite & $\mathrm{NaOCl}$ & $7681-52-9$ & 74.44 & Aldrich (Sigma-Aldrich, St Louis, MO, USA) \\
\hline Sulfosalicylic acid (dihydrate) & SSA & $5965-83-3$ & 254.21 & Acros Organics (Geel, Belgium) \\
\hline Tricine & & $5704-04-1$ & 179.17 & Sigma (Sigma-Aldrich, St Louis, MO, USA) \\
\hline
\end{tabular}

with $E t h_{\text {sample }}$ and $E t h_{\text {blank }}$ (ppm) being the measurements of the sample and corresponding blank respectively, $p_{\mathrm{i}}(\mathrm{Pa})$ the pressure before measurement, $V_{\text {free }}$ $\left(\mathrm{m}^{3}\right)$ the free headspace volume in the GC vial, $R$ the universal gas constant $\left(8.314 \mathrm{~J} \cdot \mathrm{mol}^{-1} \cdot \mathrm{K}^{-1}\right)$ and $T$ the temperature (K).

The in vitro activity of ACO (mol.g $\left.\mathrm{FW}^{-1} \cdot \mathrm{h}^{-1}\right)$ is expressed as:

$$
A C O_{\text {activity }}=\frac{n_{\text {sample }} \cdot V_{\text {extract }}}{V_{\text {reading }} \cdot w \cdot t}
$$

with $V_{\text {reading }}(\mathrm{mL})$ the amount of extract used in the reading, $V_{\text {extract }}(\mathrm{mL})$ the volume of the liquid in the sample after extraction, $w$ (g FW) the weight of the sample and $t(\mathrm{~h})$ the incubation time.

\section{Comments}

In this manuscript we provide a detailed and up to date set of protocols to measure all ethylene biosynthetic intermediates based on literature and personal observations. The protocols have been extensively tested for apple and tomato and are a good starting point for any ethylene related research. Table 1 provides an overview of the range of results that can be expected for unripe and ripe apple and tomato fruit, for the various protocols. When working with different products it is advisable to verify the efficiencies of the ACC turnover in protocol 2 and to adjust the ratios of the components in the mixture if necessary. In protocol 4 , the incubation time of the ACO extract should be checked and if necessary optimized by measuring the variation in $\mathrm{ACO}$ enzyme activity over time. The increase in activity should be linear within the time frame used. It is also important to check the literature for the optimum $\mathrm{pH}$ of ACS and ACO, and for possible alternative buffers which might yield a higher activity for other type of samples.

\section{Materials}

Table 2 contains an overview of all the chemical products used in the protocols.

The GC used was a Compact GC (Interscience, Louvain La Neuve, Belgium) equipped with a Porabond $\mathrm{Q}$ column (ID $0.53 \mathrm{~mm}$ ) and FID detector.

In the protocols three different types of centrifuges are used depending on the sample volume and the required speed: Eppendorf Centrifuge 5417 R (Eppendorf, New York, United States), Rotina 48 R (Hettich GmbH, Tuttlingen, Germany) and UniCen 15 DR (Herolab GmbH, Wiesloch, Germany).

The PD-10 desalting columns used in protocol 3 are prepacked disposable columns containing Sephadex ${ }^{\mathrm{TM}}$ G-25 Medium (GE Healthcare Europe, Diegem, Belgium).

\section{List of abbreviations used}

ACC: 1-Aminocyclopropane-1-carboxylic acid; ACO: 1-Aminocyclopropane-1carboxylate oxidase; ACS: 1-Aminocyclopropane-1-carboxylate synthase; CELIF: Capillary electrophoresis with laser-induced fluorescence detection; CA: Controlled atmosphere; GC: Gas chromatography; GC-MS: Gas chromatography-mass spectrometry; LC-MS: Liquid chromatography-mass 
spectrometry; MACC: 1-(Malonylamino)cyclopropane-1-carboxylic acid; PALS: Photo acoustic laser spectrophotometry; SAM: S-Adenosyl-L-methione

\section{Acknowledgements}

The research was funded by PhD grants of the Institute for the Promotion of Innovation through Science and Technology in Flanders (IWT-Vlaanderen) to I. Bulens and B. Van de Poel. The authors also thank the researchers of the group of Prof. De Proft (KU Leuven, Belgium) and the group of Prof. Larrigaudière (University of Lleida, Spain) for their help with the optimisation of the protocols and Dr. M.W. Davey (KU Leuven, Belgium) for his contribution with the correction of the manuscript.

\section{Author details}

'Division of Mechatronics, Biostatistics and Sensors (MeBioS), Department of Biosystems (BIOSYST), Katholieke Universiteit Leuven, Willem de Croylaan 42, bus 2428, B-3001 Leuven, Belgium. ${ }^{2}$ Division of Crop Biotechnics,

Department of Biosystems (BIOSYST), Katholieke, Universiteit Leuven, Willem de Croylaan 42, bus 2427, B-3001 Leuven, Belgium.

\section{Authors' contributions}

$\mathrm{IB}$ and $\mathrm{BV} \mathrm{dP}$ designed the study and carried out the experimental work. IB drafted the manuscript. $\mathrm{MH}$ guided the design of the experiments, the interpretation of the results and the writing of the manuscript. AG and BN contributed to the experimental design and the data interpretation. MDP participated in the optimization of the ACC protocol. BVdP and MH revised the manuscript critically and extensively. All authors read and approved the final manuscript.

\section{Competing interests}

The authors declare that they have no competing interests.

Received: 2 March 2011 Accepted: 23 June 2011

Published: 23 June 2011

\section{References}

1. Adams DO, Yang SF: Ethylene biosynthesis - identification of 1aminocyclopropane-1-carboxylic acid as an intermediate in the conversion of methionine to ethylene. P Natl Acad SCI USA 1979, 76(1):170-174.

2. De Greef JA, De Proft MP: Kinetic measurements of small ethylene changes in an open system designed for plant physiological studies. Physiol Plantarum 1978, 42(1):79-84.

3. Bassi PK, Spencer MS: Comparative evaluation of photo-ionisation and flame ionisation detectors for ethylene analysis. Plant Cell environ 1985, 8:161-165.

4. Cristescu SM, Persijn ST, Te Lintel Hekkert S, Harren FJM: Laser-based systems for trace gas detection in life sciences. Appl phys B-lasers O 2008, 92:343-349.

5. Lizada MCC, Yang SF: Simple and sensitive assay for 1-aminocyclopropane1-carboxylic acid. Anal Biochem 1979, 100(1):140-145.

6. Petritis K, Koukaki G, Koussissi E, Elfakir C, Dreux M, Dourtoglou V: The simultaneous determination of 1-aminocyclopropane-1-carboxylic acid and cyclopropane-1,1-dicarboxylic acid in lycopersicum esculentum by high-performance liquid chromatography - electrospray tandem mass spectrometry. Phytochem Analysis 2003, 14(1):347-351.

7. Smets R, Claes V, Van Onckelen HA, Prinsen E: Extraction and quantitative analysis of 1-aminocyclopropane-1-carboxylic acid in plant tissue by gas chromatography coupled to mass spectrometry. J Chromatogr A 2003, 993(1):79-87.

8. Liu X, Li DF, Wang Y, Lu YT: Determination of 1-aminocyclopropane-1carboxylic acid in apple extracts by capillary electrophoresis with laserinduced fluorescence detection. J Chromatogr A 2004, 1061(1):99-104.

9. Hoffman NE, Yang SF: Identification of 1-(malonylamino)cyclopropane1-carboxylic acid as a major conjugate of 1-aminocyclopropane-1carboxylic acid, an ethylene precursor in higher plants. Biochem Bioph Res Co 1982, 104(2):765-770.

10. Vilaplana R, Soria Y, Valentines MC, Larrigaudiere C: Specific response of apple skin and pulp tissues to cold stress and 1-mcp treatment. Postharvest Biol Tec 2007, 43(1):215-220.
11. Dandekar AM, Teo G, Defilippi BG, Uratsu SL, Passey AJ, Kader AA, Stow JR Colgan RJ, James DJ: Effect of down-regulation of ethylene biosynthesis on fruit flavor complex in apple fruit. Transgenic Res 2004, 13(1):373-384.

12. Moffatt BA, Weretilnyk EA: Sustaining S-Adenosyl-L-methioninedependent methyltransferase activity in plant cells. Physiol Plantarum 2001, 113(1):435-442.

13. Van de Poel B, Bulens I, Lagrain P, Pollet J, Hertog MLAT, Lammertyn J, De Proft MP, Nicolai BM, Geeraerd AH: Determination of $s$-adenosyl-Imethionine in fruits by capillary electrophoresis. Phytochem Analysis 2010, 21(1):602-608.

doi:10.1186/1746-4811-7-17

Cite this article as: Bulens et al: Protocol: An updated integrated methodology for analysis of metabolites and enzyme activities of ethylene biosynthesis. Plant Methods 2011 7:17.

\section{Submit your next manuscript to BioMed Central and take full advantage of:}

- Convenient online submission

- Thorough peer review

- No space constraints or color figure charges

- Immediate publication on acceptance

- Inclusion in PubMed, CAS, Scopus and Google Scholar

- Research which is freely available for redistribution

Submit your manuscript at www.biomedcentral.com/submit
Ciomed Central 